\title{
COVID-19 and Dentistry: A Review
}

\section{Ferial Hamed Almokayad*}

Dental Intern, Almustaqbal University, Saudi Arabia

*Corresponding Author: Ferial Hamed Almokayad, Dental Intern, Almustaqbal University, Saudi Arabia.
Received: August 06, 2021

Published: August 26, 2021

(C) All rights are reserved by Ferial Hamed Almokayad.

\section{Abstract}

Covid-19 is from family member of coronavirus. COVID-19 has as its etiologic agent the severe acute respiratory syndrome, spreading globally, resulting in the 2019 - 2020 pandemic, as announced by the World Health Organization (WHO). The first cases of the infection were reported in Wuhan, China, in December 2019 and January 2020. The spread of infection by droplet of infected person, the infection rapidly spread across the world, Dentists are often the first line of healthcare worker are primary responses for these lesion, as they work in close contact with patients. The entire dental teams should be alert and keep patients and themselves in a safe environment by wearing PPE and following the guideline from WHO.

Keywords: Covid-19; Dentistry; Infection Control

\section{Introduction}

There were many reports related of transferred pathogens from animals to humans rapidly evolving into transmission from human to human. The disease was named corona virus (COVID-19). Coronaviruses belong to the Coronaviridae family including large, single, plus-stranded RNA as the genome. primarily infect the respiratory, gastrointestinal, and central nervous function of humans and mammals. Transmission occurs through droplet spread or direct or indirect contact routes. Due to working of dental practice, the risk of cross infection between healthcare provider and patients is very high. The most recommended guidelines indicate that healthcare provider should avoid giving appointment of any patient with any respiratory disease and management of only such emergency cases of dental diseases as sever pulp pain during the COVID-19 outbreak. This action will limit the personal contact, on the other hand the waiting time of patients in waiting area could getting patients to be infected. When the dentists treat patients, they should checked of any sign high fever, cough and shortness of breath and questioned about there general health and if they contact with any infected person last 14 days before they reach the operating areas. Dental procedures involve the use of rotary instruments produce aerosols. The dentists should wear personal protective equipment, standard precaution to prevent spread of infection and to reduce the transmission of bloodborne droplet and other pathogens from both recognized and unrecognized sources.

\section{Covid-19 transmission}

According to results from genetic and epidemiologic studies, the COVID-19 outbreak began with a single transmission from animal to human and then continue transmitted from human-to-human. The most possible transmission pathways of covid-19 is direct transmissions such as sneeze, cough, and inhalation of airborne 
particles and contact with the oral, eye, nose. Although typical clinical presentations of covid-19 do not contain eye symptoms, but may be a potential way for the virus to penetrate the body. Covid-19 can also be transmitted by saliva droplet.

\section{Guidelines and infection control}

WHO guidelines washing of hand before and after contact with the patient. Performing hand hygiene frequently with hand sanitizer with al 70\% ethanol. A detailed history should be taken from the patients by asking them to fill the form of COVID-19 infection its an essential tool for correct identification before any dental practice, using of rubber dam reduced the aerosol by $70 \%$ that considered less risk of infection by reducing communication with oral fluid.

High-speed rotary instruments used with an anti-retraction system and high volume vacuum(evacuator) which is removes 0.5 litres of water in 2 seconds and removes $100 \%$ solids during clinical procedure to prevents the release of debris and fluids that can may be inhaled by dentists during clinical procedures. In the case of severe pain of pulp, therapy with non-steroidal anti-inflammatory drugs, such as ibuprofen, and antibiotics.

Protocol during dental procedure to be followed:

1. Hand hygiene

2. Personal protective equipment (PPE)

3. Pre-procedural mouthrinse

4. Rubber dam

5. Single-use tools

6. Reduce aerosol production

7. Disinfection of the surface

8. Medical waste disposal [1-4].

\section{Conclusion}

Covid-19 is not the only viruses threatens our live, protecting ourselves by following infection control guideline, keep distance 2 meters between you and other person.

\section{Bibliography}

1. Villani FA., et al. "COVID-19 and Dentistry: Prevention in Dental Practice, a Literature Review" (2020).
2. Baghizadeh Fini M. "What dentists need to know about COVID-19”. Oral Oncology 105 (2020): 104741.

3. ADA guideline-coronavirus update.

4. Spagnuolo G., et al. “COVID-19 Outbreak: An Overview on Dentistry". International Journal of Environmental Research and Public Health 17.6 (2020): 2094.

Volume 5 Issue 9 September 2021

(C) All rights are reserved by Ferial Hamed Almokayad. 